\title{
Determining Order Delivery Date by Revenue Approach: A Case Study with Non-Woven Textile Manufacturers in TRC1 Region
}

\author{
Cemal Aktürk ${ }^{1}$ Sevinç Gülseçen ${ }^{2}$ \\ ${ }^{1}$ Kilis 7 Aralık University, Faculty of Engineering and Architecture, Computer Engineering, Kilis, Turkey \\ ${ }^{2}$ İstanbul University, Informatics Department, İstanbul, Turkey
}

Corresponding Author: Cemal Aktürk, cakturk@kilis.edu.tr

\begin{abstract}
Non-woven textile materials are used as intermediate raw materials in various sectors such as cleaning, healthcare and automotive. These products are produced based on demand because they are requested in different compositions, colors, and weights. To ensure that the company achieves its objectives, it is necessary to use the capacity efficiently in the non-woven textile technology since it has high investment costs and high production capacity. In this study, a decision support system has been developed for non-woven textile firms so that they can obtain more order revenue. This software application was developed to sort the orders in 7 different ways based on the Moora and linear functions. The total order revenues to be obtained from each ranking and the delivery dates of sorted jobs are calculated and presented to the user to help him/her in the decision-making process. In addition, this software can also record the operator's planned maintenance data. In the present study, the decision support system was run with 27 different production scenarios. In the scenarios, the Moora method and linear function methods put forward more total order revenues than FCFS (First Come First Served) and EDD (Earliest Due Date) methods. As a product that can be used by decision-makers, the present decision support system provides a different point of view to the literature -which generally consists of theoretical studies- on delivery date and order ranking.
\end{abstract}

\section{ARTICLE HISTORY \\ Received: 29.05.2018 \\ Accepted: 06.05.2019}

\section{KEYWORDS}

Non-woven textile, order ranking, decision support system, moora, delivery date

\section{INTRODUCTION}

Companies which produce according to the order size respond to their customers' requests with an offer including the product price and product delivery date. Order proposals with a late delivery date lead to loss of customers or even market loss. Accepting the delivery date requested by each customer also leads to the capacity buildup for the manufacturer. There may be customers who want to pay more to get a product earlier, or there may be customers who want to pay less to get a non-urgent order later than the actual delivery date. For this reason, in addition to the price, the delivery date of the product is also a negotiable subject between the customer and the producer.

Delivery date assignment rules are basically derived from common delivery date, equal slack, and total work time methods. This study is based on total work time. Considering the recent studies, Guhlich and his team have proposed a demand management model that includes businesses which adopt the assemble-to-order strategy for profit maximization in revenue management [1]. In our study, it has been optimized with linear function 2 for the orders that are delayed according to the demand date of the customers. Similarly, in another study, a binary tree data structure method was used to determine the common due date with a little delay for the flow of two sequential jobs [2]. Also, a study was conducted to optimize the penalties from all jobs by adding some idle time in a single-machine planning environment [3], assuming punishment of early and late delivery dates. An integrated delivery date assignment method with process planning, genetic algorithm, and random search techniques was proposed in another study

To cite this article: Aktürk, C., Gülseçen S. 2019. Determining order delivery date by revenue approach: a case study with non-woven textile manufacturers in TRC1 region. Tekstil ve Konfeksiyon, 29(2), 133-141. 
[4]. The total weighted delay cost was tried to be reduced in one study by applying two different delay costs according to the double delivery date and the time spent in delayed jobs [5]. Besides, a formulation study was carried out for the single-machine stochastic model to compensate for the delay of the ordered jobs and the delay of the delivery dates [6]. In addition, the problem of minimizing the costs associated with delays was investigated [7]. In another study, mixed integer linear programming and dynamic programming methods were tested on a large data set in a single machine environment to minimize the total early delay with a common delivery date [8]. One study aimed to minimize the cost penalty function, which includes total early penalties such as delay [9]. A dynamic programming algorithm and a polynomial-time approximation scheme were proposed in another study to minimize a cost function involving the number of late jobs and the delivery date [10]. A study aimed to minimize the number of late jobs whose delivery dates were not known precisely [11]. In a study, the relationships among the performance criteria such as delay, relative delay, and timing reliability from the feedbacks of the four real producer firms were analyzed statistically [12]. To obtain realistic results, planned maintenance periods and production setup times of the enterprises were also included in the time calculations. In a single-machine planning environment, a study was conducted with the intention of reducing the absolute deviations of completion times of jobs for a common delivery date, considering scheduled maintenance periods [13]. It was aimed to reduce the total delay to the minimum by using the setup-by-task duration feature in another study [14]. A study examined total cost minimization including inventory cost, installation cost, preventive and corrective maintenance cost and reprocessing cost to balance the inventory cost and maintenance cost in a mass production environment [15]. In a study, an approach was proposed that accepts the capacity as stochastic for the number of machines, maintenance and fault conditions [16]. To reduce the cost of assigning the total weighted number of jobs and the deadline, an approach scheme using a polynomial algorithm was proposed in a study [17]. Integrated process planning, scheduling, and delivery date assignment problems were studied in another study [18]. A study emphasized that the genetic algorithm provides the best solution for the same problem [19]. In contrast to the setup times used in the calculations in this study, workshop scheduling problems were studied by assuming there was no waiting period between consecutive jobs [20]. Another study stressed that the integration of product design and production is closely related to the problem of delivery date [21]. Unlike the method of accumulating orders in a pool, the batch scheduling problem was studied for a dynamic flow factory environment in which a new incoming order would be added to the existing workload [22]. Finally, order sorting activity was analyzed according to the earliest delivery date [23].

Non-woven textiles, which are the subject of this study, are commonly used as intermediate products for wet wipes, nappies, and disposable medical supplies. Such materials are produced based on orders from customers because they specify their preferences for various properties such as raw material composition, weight, and color. This study proposes a decision support system based on revenue approach to help non-woven textile companies with order sequencing and order delivery date calculation. The orders are sorted by seven different methods with this proposed model. The total order revenues obtained from each order made for a certain planning period are presented as decision support to the marketing unit managers. At the same time, any sorting method can be selected, and delivery dates can be assigned to sequenced orders of that method in the system. This article contributes to the literature with a new perspective of multi-criteria decisionmaking methods and decision support system.

\section{MATERIAL AND METHOD}

\subsection{Linear Function}

The method proposed as a linear function is a simple and useful method of mathematical decision making and is expressed by the weighted sum of criteria. In this article, customer and order are determined as the main criteria for order sorting criteria. The customer-related main criteria are as follows: the number of years which the customer has been working with the company, the annual turnover rate of the company from the customer, and the annual total order amount of the customer. The order-related criterion is only the total amount of the relevant order. The principal criterion of the customer is shown in Equation (1), order criterion in Equation (2), and $F$ is shown in Equation (3). In the equation (1); $X_{1}, X_{2}$ and $X_{3}$ criteria are customer's annual order amount, customer's annual order count, and the number of years the company has been working with the customer, respectively. Also, $X_{4}$ criteria in Equation (2) is the order amount. The $F$ function from these linear functions is the objective function used in sorting the orders. The sum of the weight coefficients used in each function has to be equal to 1 as shown in Equation (4). Criteria expressed by different units and sizes in linear functions are subjected to normalization process by being divided into maximum criterion values. In this case, each criterion is transformed into a size between 0 and 1 , and the objective function $(F)$ consisting of the weighted sum of these criteria is obtained.

$$
\begin{aligned}
& M(i)=w_{1} X_{1}+w_{2} X_{2}+w_{3} X_{3} \\
& S(i)=X_{4} \\
& F(i)=W_{1} M(i)+W_{2} S(i) \\
& \sum_{i=1}^{n} W i=1
\end{aligned}
$$

\subsection{Moora (Multi-Objective Optimization by Ratio Analysis)}

The Moora method is an easy and convenient method that can provide effective results with simple mathematical calculations within multi-criteria decision-making techniques. The Moora method is based on ratio analysis because of the normalized criterion values obtained by dividing each criterion value by the square root of the sum of squares of all criterion values, as shown in Equation (5). For each alternative in the Moora method, as shown in Equation (6); normalized values of the maximizing and minimizing criteria are aggregated within themselves. Then the value of $Y_{i}{ }^{*}$, which is the difference between maximized and minimized sums, is calculated. The decision-making process is 
completed by selecting the alternatives with large $Y_{i}$ values, sorting the alternatives from large to small according to this $Y_{i}^{*}$ value. If it is desired to apply a certain importance coefficient for each alternative, the Moora-significance coefficient method can be used by multiplying the calculated $Y_{i}$ values by the desired weight coefficient $w$ in the last case. $F(i)$ function calculated from the linear method is multiplied by $Y_{i}$ value calculated by the Moora method, and Moora significance coefficient method is used by specifying the weighted Moora. The reference point approach, which is another Moora method, is also an effective method based on ratio analysis. After the normalization process is completed, the best criterion value for each criterion is determined as the reference value, and the distances from the reference values of the relevant alternatives are calculated as in Equation (7) by taking the difference of the relevant criterion value from the determined reference value. After calculating the differences from the best value in this way for each criterion, the alternatives are selected as the alternative decision with the smallest digits in ascending sort according to the value of $d_{i j}$.

$$
\begin{aligned}
& X_{i j}^{*}=\frac{x_{i j}}{\sqrt{\sum_{j=1}^{m} x_{i j}^{2}}} \\
& Y_{i}^{*}=\sum_{j=1}^{g} X_{i j}^{*}-\sum_{j=g+1}^{n-g} X_{i j}^{*} \\
& d_{i j}=r_{i}-X_{i j}^{*}, \min _{i} \max _{j}\left(d_{i j}\right)
\end{aligned}
$$

\subsection{AHP (Analytic Hierarchy Process)}

To get expert opinions, nine non-woven textile companies actively operating in the region, determined with the help of Gaziantep Chamber of Industry, were interviewed. six companies agreed to contribute to the research. The weighting coefficients used in the decision models were derived from the AHP questionnaire applied to the marketing unit managers of non-woven textile firms (Table 1). Participants indicated a more important criterion by marking the relevant numbers. As the geometric average of the criteria weights was taken within the scope of the expert opinion, six participants were deemed sufficient. The weight coefficients obtained from the study [30] and used in the decision model are shown in Table 1. The weight coefficients obtained from the AHP questionnaire and other weight coefficients used in decision models are shown in Table 2.

\subsection{Capacity Calculation Method}

The factory production line based on the study is as follows:

1. Fiber comb machine

\section{Hydro-entanglement machine}

3. Water removal and air dryer machine

4. Winder

The capacity of the non-woven textile production line in the company from where the data are received is calculated by the kilogram of fibers $(28 \mathrm{~kg} / \mathrm{min})$ that can be combed per minute by the fiber comb machine which constitutes the first entry of the production line. In all the factories participating in the study, the production speed depends on this machine because it is the first machine of the line and its capacity speed is the least among the product line's other machines. Although other machines can run faster, they work within this speed limitation because they work synchronously with the fiber comb machine. Its combing speed is $28 \mathrm{~kg} / \mathrm{min}$. This data is used to calculate how many minutes it will take for each order to be produced. In non-woven production, the size in grams of the fibers per square meter (weight) is a critical detail. Because the amount of fiber that the production line can process in $\mathrm{kg}$ is limited and constant, the low weight textiles travel at a higher speed in the production line. Thus, textiles with more weight travel at a lower speed. Since total production capacity is constant, the time amount of each order to be produced according to the weightfeature of order records is calculated with the following formulas.

$$
\begin{aligned}
& H_{1}=K .1000 / G_{i} \\
& H_{2}=H_{1} / W \\
& T_{i}=\frac{M_{i}}{W} / H_{2}
\end{aligned}
$$

Table 1. AHP questionnaire used in determining weight coefficients of criteria

\begin{tabular}{llllllllllll}
\hline Amount of Customer's Annual Orders & 9 & $\mathbf{7}$ & $\mathbf{5}$ & $\mathbf{3}$ & $\mathbf{1}$ & $\mathbf{3}$ & $\mathbf{5}$ & $\mathbf{7}$ & $\mathbf{9}$ & Number of Customer's Annual Orders \\
Amount of Customer's Annual Orders & $\mathbf{9}$ & $\mathbf{7}$ & $\mathbf{5}$ & $\mathbf{3}$ & $\mathbf{1}$ & $\mathbf{3}$ & $\mathbf{5}$ & $\mathbf{7}$ & $\mathbf{9}$ & Number of Years Worked with the Customer \\
Number of Customer's Annual Orders & $\mathbf{9}$ & $\mathbf{7}$ & $\mathbf{5}$ & $\mathbf{3}$ & $\mathbf{1}$ & $\mathbf{3}$ & $\mathbf{5}$ & $\mathbf{7}$ & $\mathbf{9}$ & Number of Years Worked with the Customer \\
Customer Main Criteria & $\mathbf{9}$ & $\mathbf{7}$ & $\mathbf{5}$ & $\mathbf{3}$ & $\mathbf{1}$ & $\mathbf{3}$ & $\mathbf{5}$ & $\mathbf{7}$ & $\mathbf{9}$ & Orders Main Criteria (Amount of Orders) \\
\hline
\end{tabular}

Table 2. Criterion weight coefficients used in production scenarios

\begin{tabular}{lccccc}
\hline Coefficients group & $\begin{array}{c}\text { Amount of } \\
\text { annual orders } \\
\mathbf{X}_{1}\end{array}$ & $\begin{array}{c}\text { Number of } \\
\text { annual } \\
\text { orders } \mathbf{X}_{2}\end{array}$ & $\begin{array}{c}\text { Number } \\
\text { of years } \\
\mathbf{X}_{3}\end{array}$ & $\begin{array}{c}\text { Customer } \\
\text { main criteria } \\
\mathbf{M}(\mathbf{i})\end{array}$ & $\begin{array}{c}\text { Orders main } \\
\text { criteria S(i) }\end{array}$ \\
\hline Coefficients obtained from research & 0.49 & 0.30 & 0.21 & 0.78 & 0.22 \\
Equal weighted customer and order criteria & 0.49 & 0.30 & 0.21 & 0.5 & 0.5 \\
Dominant order main criteria (Reverse of the Research) & 0.49 & 0.30 & 0.21 & 0.22 & 0.78 \\
\hline
\end{tabular}


In Equation (8), $\mathrm{H}_{1}$ is the production speed calculated in square meters; $K$ is the capacity of the production line defined in kilograms/minute; $G_{i}$ refers to the weight of the product ordered. In Equation (8), first, the speed of the production line is multiplied by 1000 and converted into grams per minute. Then it is divided by weight in grams to calculate the production speed in square meters per minute. In Equation (9), $H_{1}$ is divided by the width of the production line in meters, and the velocity in meters per minute is calculated. The $\mathrm{H}_{2}$ variant is used to calculate the processing times of orders. In Equation (10), $\mathrm{M}_{\mathrm{i}}$ denotes to the order quantity in square meters. $\mathrm{T}_{i}$ indicates the processing time of the order in minutes. The order quantity taken as a square meter is firstly converted to the meter by dividing it by $\mathrm{W}$ value which is the width of the production line of the company in meters. It is then divided by $\mathrm{H}_{2}$, which is calculated in meters/minute, to obtain the amount of time for the order to be produced. In the latter case, the $T_{i}$ value is calculated for each order to find out the amount of time for each order to be produced. The characteristics of the production environment in which the decision support system is operated are as follows: production speed is $28 \mathrm{~kg} / \mathrm{min}$, the production line width is 1.6 meters, and average preparation time between productions is 20 minutes. The number of working hours per day was determined as $8,12,16$ and 24 in various production scenarios used throughout the study. It was assumed that the firm works on Sundays. If desired, Sundays can be excluded from the working days by ticking "no" in the application software. The decision support system was operated according to the conditions mentioned above for various periods of 7 and 28 days as well as using different weighting factors.

\subsection{Developed Decision Support System}

In this article, it has been shown that non-woven producers can get more revenue by sorting customers' orders according to the criteria recommended by application software developed in C \#.net. Application software consists of seven different methods; linear function1, linear function2 (optimized linear function1), Moora-ratio method, weighted Moora, Moora reference point approach, FCFS, and EDD. Then, with these methods, the total revenue that can be obtained from the orders sortedin a specific planning horizon is presented to the decision maker. Which model will offer better revenue according to the case depends on weight coefficients, order, and customer data. For this purpose, seven methods are presented at the same time, and the method that offers the most revenue is presented to the user. Marketing unit managers, who are the users of the system, can offer their customers delivery dates calculated according to sequential orders that are the output from the method that recommends more order revenue and can perform the production schedule. In the application software, the same delivery date assignment function is used for orders placed following seven different sorting methods. It is intended to produce realistic results by checking that the company has a predefined planned maintenance record for future dates when the due date is assigned. In the system development phase, the production processing times and delivery dates for each order according to the actual order quantities were calculated by the system for five different sample scenarios and the results were verified by the relevant production engineers. The process steps of the delivery date assignment function are shown in Figure 1. In Figure 2, the flow of the linear function2 method, including the optimization operations, to the linear function1 is shown. In the FCFS method, orders are sorted according to the order in which they are added to the database. In the EDD method, orders are sorted according to the date requested by the customer. The ranking of the Moora method is done with $Y_{i}$ (Equation 6), the Moora reference point is done with $d_{i j}$ (Equation 7) and weighted Moora is done by multiplication of $F$ and $Y_{i}$ values of Equations (3) and (6) described above.

When the application software is run, the main menu form shown in Figure 3 is displayed. In the form of parameters, the definitions of the weighting coefficients in decision models are made. Customer data is recorded on the customer form. In the maintenance form, the start and end times of the company's planned maintenance work and maintenance periods are defined. In the form of operations, data such as the production capacity $(\mathrm{kg} / \mathrm{min})$ used to calculate the processing times of the orders, the number of daily working hours of the business, the start time of work, and the working status on Sundays are recorded.

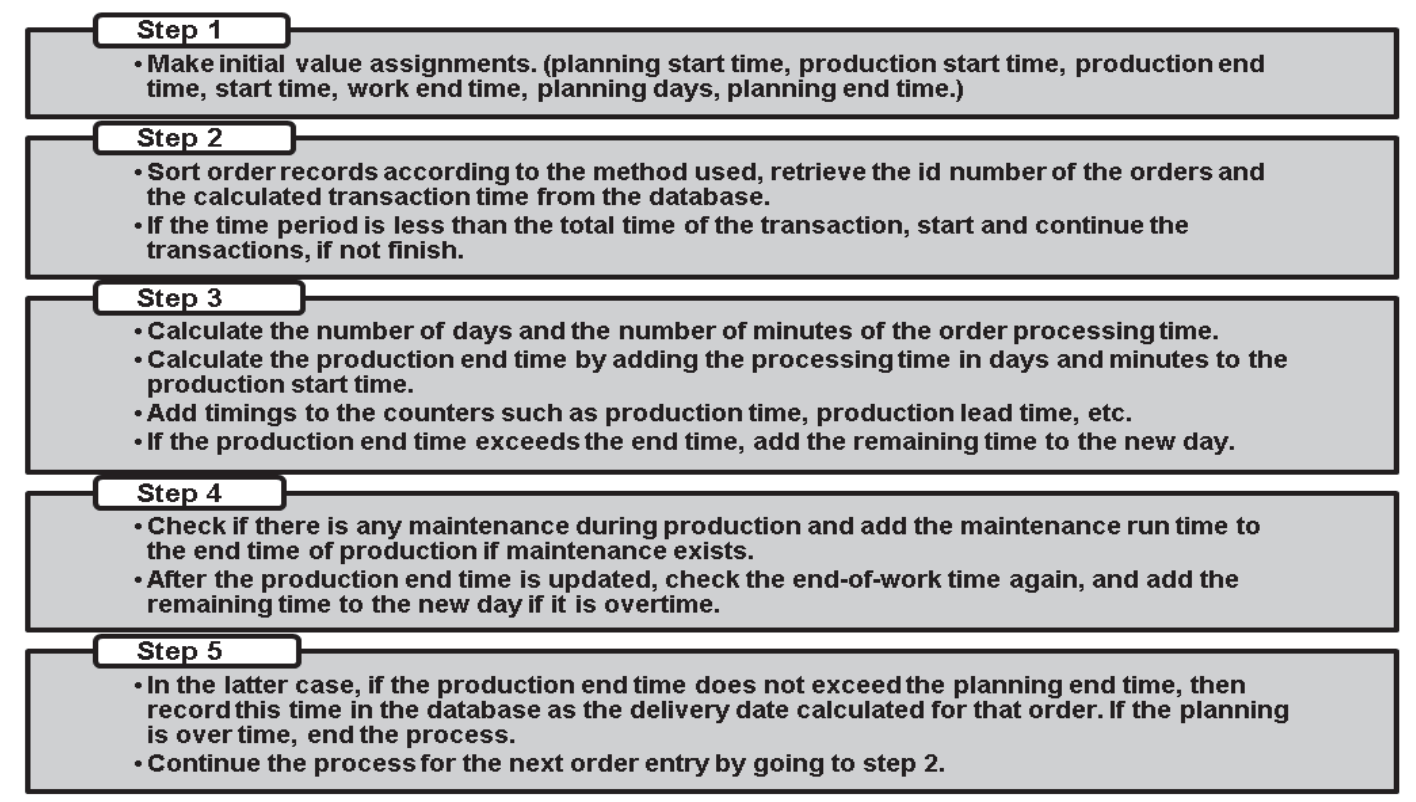

Figure 1. Delivery date assignment process steps 


\begin{tabular}{l}
\hline Step 1 \\
- Retrieve the order records with status = "LATE" from the database in ascending order \\
of their delivery dates. \\
\hline Step 2 \\
- For each of the order records in step 1; take orders from the database earlier than this \\
order's due date. \\
\hline Step 3 \\
- Assign the demand dates and delivery dates of the orders with the status "LATE" and \\
- if (Late Order's delivery date < $<$ early order's delivery date) and (early order's calculated \\
delivery date <= Late order's demand date) replace the values of Fi that specify the \\
sequence of the orders, save it to the database. \\
\hline Step 4 \\
- Run delivery date assignment function \\
- Run the optimization function. \\
- Continue to make flexible orders from step 2 as appropriate to improve these LATE \\
orders.
\end{tabular}

Figure 2. Linear 2 function process steps

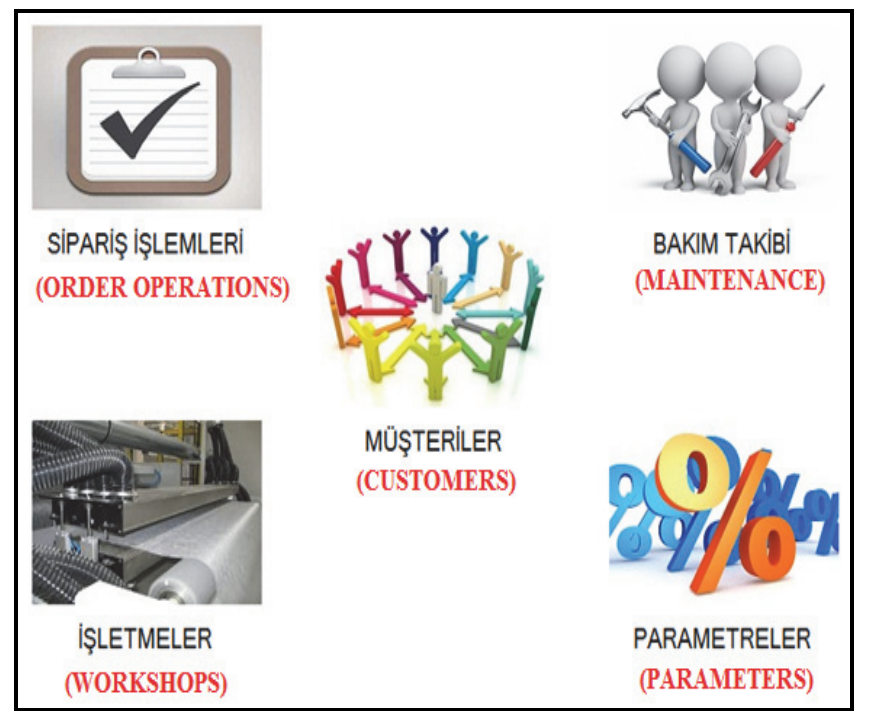

Figure 3. Main menu screenshot

In the form in Figure 4, the 1st tab is saved by importing batches individually or from excel file. At the 2nd tab, order sorting operations are performed. Some buttons, tabs, and text boxes are shown with the same number to describe the screen display in Figure 4. Objects with the same number belong to the same method. Linear function 1 3(obtained by Equation 3), linear function2 4(obtained by applying the steps shown in Figure 2 to Equation 3), FCFS 5, EDD 6, Moora 7, Weighted Moora 8, and Moora Reference point 9 are numbered. For example, when button 3 is pressed, the linear function 1 method operates. The total order revenue that Linear Function1 suggests is shown in textbox 3 on the right side of the screen, while the details of the sorted orders are shown on tab 3 . The other objects in Figure 4 are as follows: The factory is selected by clicking on number 10 . The start time of the production plan is entered by clicking on number 11 , and by clicking on number 12 , the number of days for the planning is specified. In the form of Workshops in Figure 3, if the start time of the production plan and the number of days for planning are defined as parametrically, this data comes automatically. Order data can be entered both manually and in excel format. The user operates the order sorting function of each method by clicking the buttons numbered from 3 to 9 . When each method is run, the total order revenues from the sorted orders are shown in the text boxes shown at the same number as the method on the left side of the screen. In this way, revenue from each method can be easily compared. Sorted orders that offer the most revenue can be reached from the tab specified by the method name, and these orders can be used in the production schedule. The application software is run with three different data setsto test and monitor the performance of the proposed models with different data: a real firm's order data, data derived from actual data, and randomly generated data. Then, the findings are recorded. The actual data consists of 19 customers and 182 orders from these customers. Derived data is generated by multiplying the production quantities registered in daily production reports by different coefficients and converting them into order quantities. There are 136 order records in the derived data. These orders are based on the customers in the actual data set. Thirty-two customers and 80 orders are recorded as random data as a separate data set.

\section{RESULTS AND DISCUSSION}

The data sets were run in the decision support system using the weighting factors in Table 2 for various planning scenarios. The purpose of creating different scenarios is to observe the maintenance process and findings in different shift hours. In addition, since the number of records in the data sets is different, the total work time is not the same. Then, the findings are recorded. The data of the findings are transferred to an excel sheet; the delivery times calculated with order quantities, production speed, and calculated processing times are checked manually. Also, the accuracy of the start time of the next order is checked by adding production preparation time to the delivery time of the previous order. Each line in the following tables refers to a running scenario. In each scenario, the maximum amount of order revenue and the amount suggested by the method are shown in bold. In the same period, the method with the highest revenue is shown in the box. Table 4 shows the findings obtained from running actual data. When Table 4 is examined, it is seen that the maximum order revenue is $3,546,483.89$ TL by working 12 hours a day for seven days a week. This amount has been obtained from the linear 
function2 method using the equal weighted customer and order criteria coefficients. When the working hours are increased to 24 hours a day, the maximum order revenue is calculated as $5,048,928.66 \mathrm{TL}$ in a 7 -day-period. This order amount is also obtained from the linear function2 method using the same coefficient group. The maximum order revenue for the 12-hour-a-day scenario for 28 days was Moora's reference point method with 8,255,614.38 TL. In Moora methods, there is no effect of weight coefficients in the decision process.
The results of the scenario in which the randomly generated data set is run in the decision support system are shown in Table 5. Working for 8 hours for 7 days, maximum order revenue is calculated as $5,746,796.00 \mathrm{TL}$. This calculation is obtained by running the linear functions with equal weighted coefficients. When the number of working hours is increased to 16 , maximum order income in 7 days is given by linear functions with equal weighted coefficients. Calculated total order revenue was $9,768,506.00 \mathrm{TL}$.

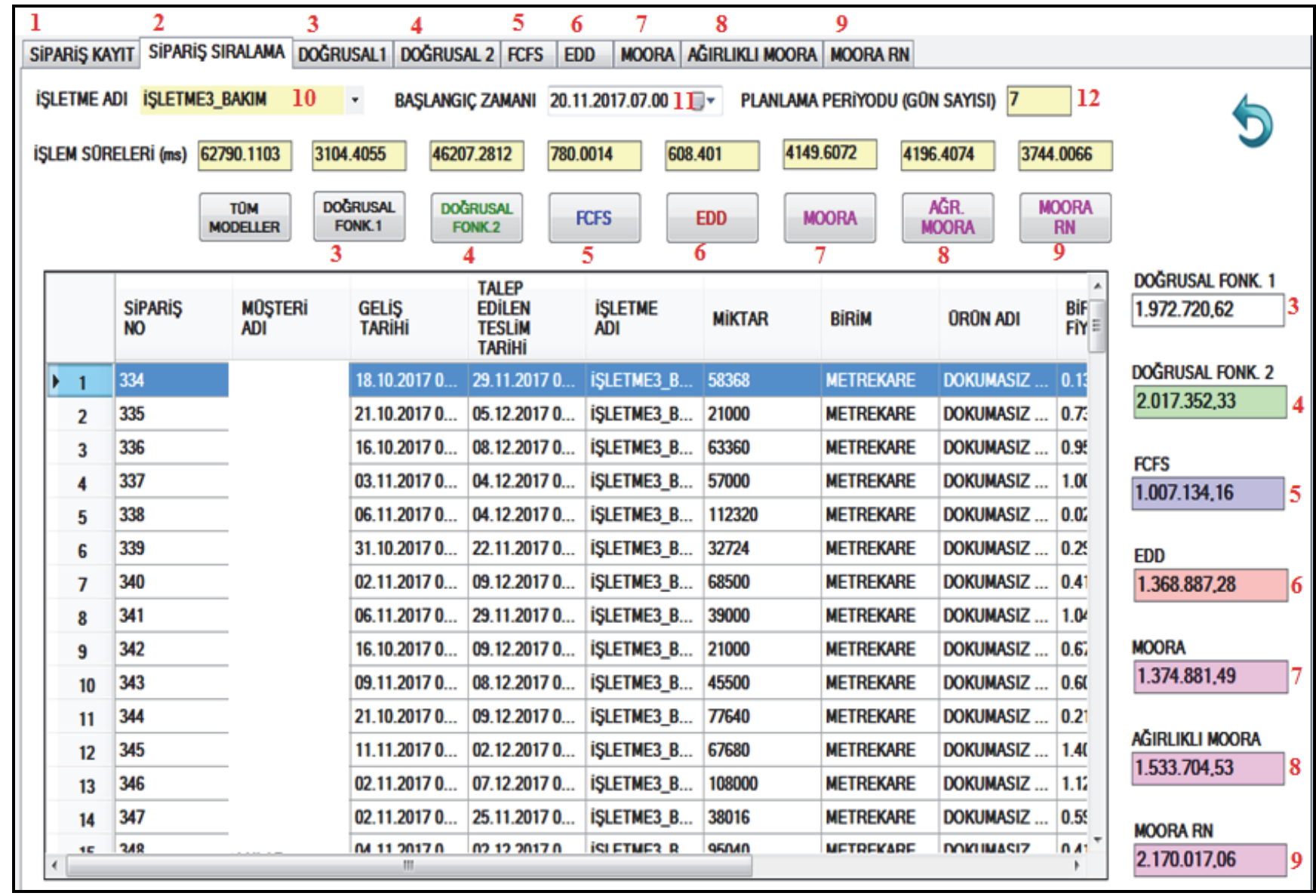

Figure 4. Order recording and ranking form screenshot

Table 4. Comparison of total order amounts (TL) of real data by models

\begin{tabular}{|c|c|c|c|c|c|c|c|c|}
\hline Capacity & $\begin{array}{l}\text { Coefficient } \\
\text { group }\end{array}$ & $\begin{array}{c}\text { Linear } \\
\text { function1 }\end{array}$ & $\begin{array}{c}\text { Linear } \\
\text { function2 }\end{array}$ & FCFS & EDD & MOORA & $\begin{array}{l}\text { Weighted. } \\
\text { MOORA }\end{array}$ & $\begin{array}{l}\text { MOORA } \\
\text { R.P. } \\
\end{array}$ \\
\hline 7 days, $12 \mathrm{~h}$ & $\begin{array}{l}\text { Research } \\
\text { coefficients }\end{array}$ & $1,663,990.63$ & $1,663,990.63$ & $1,684,863.40$ & $1,864,989.83$ & $2,806,936.00$ & $2,033,765.26$ & $2,806,936.00$ \\
\hline 7 days, $12 \mathrm{~h}$ & $\begin{array}{l}\text { Equal weighted } \\
\text { coefficients }\end{array}$ & $3,361,597.26$ & $3,546,483.89$ & $1,684,863.40$ & $1,864,989.83$ & $2,806,936.00$ & $2,806,936.00$ & $2,806,936.00$ \\
\hline 7 days, $12 \mathrm{~h}$ & $\begin{array}{l}\text { Dominant order } \\
\text { main criteria }\end{array}$ & $3,361,597.26$ & $3,361,595.89$ & $1,684,863.40$ & $1,864,989.83$ & $2,806,936.00$ & $2,806,936.00$ & $2,806,936.00$ \\
\hline 7 days, $24 \mathrm{~h}$ & $\begin{array}{l}\text { Research } \\
\text { coefficients }\end{array}$ & $4,662,344.66$ & $4,855,636.66$ & $2,478,334.03$ & $4,138,574.07$ & $4,179,114.66$ & $4,179,114.66$ & $4,494,017.89$ \\
\hline 7 days, $24 \mathrm{~h}$ & $\begin{array}{l}\text { Equal weighted } \\
\text { coefficients }\end{array}$ & $4,662,344.66$ & $5,048,928.66$ & $2,478,334.03$ & $4,138,574.07$ & $4,179,114.66$ & $4,179,114.66$ & $4,494,017.89$ \\
\hline 7 days, $24 \mathrm{~h}$ & $\begin{array}{l}\text { Dominant order } \\
\text { main criteria }\end{array}$ & $4,727,361.33$ & $5,017,299.33$ & $2,478,334.03$ & $4,138,574.07$ & $4,082,468.66$ & $4,275,760.66$ & $4,977,247.89$ \\
\hline 28 days, $12 \mathrm{~h}$ & $\begin{array}{l}\text { Research } \\
\text { coefficients }\end{array}$ & $7,479,897.43$ & $7,479,897.43$ & $4,518,479.45$ & $7,728,005.15$ & $7,600,436.07$ & $7,383,881.66$ & $8,255,614.38$ \\
\hline 28 days, $12 \mathrm{~h}$ & $\begin{array}{l}\text { Equal weighted } \\
\text { coefficients }\end{array}$ & $7,849,453.86$ & $7,849,453.86$ & $4,518,479.45$ & $7,728,005.15$ & $7,600,436.07$ & $7,823,092.43$ & $8,255,614.38$ \\
\hline 28 days, $12 \mathrm{~h}$ & $\begin{array}{l}\text { Dominant order } \\
\text { main criteria }\end{array}$ & $7,945,851.12$ & $7,945,851.12$ & $4,518,479.45$ & $7,728,005.15$ & $7,600,436.07$ & $7,945,851.12$ & $8,255,614.38$ \\
\hline
\end{tabular}


Table 5. Comparison of total order amounts (TL) of random generated data by models

\begin{tabular}{|c|c|c|c|c|c|c|c|c|}
\hline Capacity & $\begin{array}{l}\text { Coefficient } \\
\text { Group }\end{array}$ & $\begin{array}{c}\text { Linear } \\
\text { function1 }\end{array}$ & $\begin{array}{c}\text { Linear } \\
\text { function2 }\end{array}$ & FCFS & EDD & MOORA & $\begin{array}{c}\text { Weighted. } \\
\text { MOORA }\end{array}$ & $\begin{array}{l}\text { MOORA } \\
\text { R.P. }\end{array}$ \\
\hline 7 days, $8 \mathrm{~h}$ & \multirow{3}{*}{$\begin{array}{l}\text { Research } \\
\text { coefficients } \\
\text { Equal weighted } \\
\text { coefficients } \\
\text { Dominant order } \\
\text { main criteria }\end{array}$} & $5,365,786.00$ & $5,365,786.00$ & $4,097,769.44$ & $4,210,821.44$ & $5,009,688.00$ & $5,365,786.00$ & $5,311,090.00$ \\
\hline 7 days, $8 \mathrm{~h}$ & & $5,746,796.00$ & $5,746,796.00$ & $4,097,769.44$ & $4,210,821.44$ & $5,009,688.00$ & $5,599,786.00$ & $5,311,090.00$ \\
\hline $\mathrm{h}$ & & $5,517,396.00$ & $5,517,396.00$ & $4,097,769.44$ & $4,210,821.44$ & $5,009,688.00$ & $5,404,836.00$ & $5,311,090.00$ \\
\hline 7 days, $16 \mathrm{~h}$ & \multirow{3}{*}{$\begin{array}{l}\text { Research } \\
\text { coefficients } \\
\text { Equal weighted } \\
\text { coefficients } \\
\text { Dominant order } \\
\text { main criteria }\end{array}$} & $8,497,217.44$ & $8,497,217.44$ & $8,849,137.44$ & $8,924,337.44$ & $8,329,137.44$ & $8,329,137.44$ & $9,739,206.00$ \\
\hline 7 days, $16 \mathrm{~h}$ & & $9,768,506.00$ & $9,768,506.00$ & $8,849,137.44$ & $8,924,337.44$ & & $8,990,465.84$ & $9,739,206.00$ \\
\hline 7 days, $16 \mathrm{~h}$ & & $9,720,056.00$ & $9,720,056.00$ & $8,849,137.44$ & $8,924,337.44$ & $8,329,137.44$ & $9,255,226.00$ & $9,739,206.00$ \\
\hline
\end{tabular}

The findings of the derived data are shown in Table 6 by considering the planned maintenance records or by ignoring the maintenance plan. When the improved decision support system is included in the calculation of planned maintenance records, production capacity decreases, and thus the order revenues decrease. The derived data were run for 12 and 24 working hours for a 7-day-period. At the same time, there was a change in income due to capacity utilization, with each scenario maintenance plan included and separately run without inclusion. In the case of working for 12 hours a day and 7 hours a week with no maintenance plan included, the maximum order income is given by linear functions with coefficients that are dominated by the order criterion. Total order amount has beencalculated as $4,636,346.81 \mathrm{TL}$ in this scenario. When the maintenance plan for the same capacity is included, the total order quantity is again obtained with coefficients that are dominated by the ordering criterion and linear function2. This time, the total order amount decreased to 4,091,049.29 TL. If the maintenance plan is omitted while the working hours are increased to 24 hours, the maximum total order amount is calculated as $5,175,435.51 \mathrm{TL}$ by Moora reference point method using the research coefficients. When the maintenance plansare also included in the same scenario, the maximum total revenue recommended by the decision support system is calculated as $4,675,502.41$ TL by the weighting coefficient, which is the predominant ordering criterion, and Moora reference point method. In both 12 hours a day and 24 hours a day cases, the decision support system has shown realistic results when the maintenance plan is included in the calculation of the operational capacity.

Table 6. Comparison of total ordered amounts ( $T L)$ of derived data by models and maintenance situations

\begin{tabular}{|c|c|c|c|c|c|c|c|c|}
\hline Capacity & $\begin{array}{l}\text { Coefficient } \\
\text { group }\end{array}$ & $\begin{array}{l}\text { Linear } \\
\text { function1 }\end{array}$ & $\begin{array}{l}\text { Linear } \\
\text { function2 }\end{array}$ & FCFS & EDD & MOORA & $\begin{array}{l}\text { Weighted. } \\
\text { MOORA }\end{array}$ & MOORA R.P. \\
\hline 7 days $12 \mathrm{~h}$ & $\begin{array}{l}\text { Research } \\
\text { Coefficients } \\
\text { Equal }\end{array}$ & $3,798,518.56$ & $3,798,518.56$ & $3,612,783.78$ & $3,465,981.07$ & $4,433,157.03$ & $4,048,355.79$ & $2,828,081.91$ \\
\hline 7 days $12 \mathrm{~h}$ & $\begin{array}{l}\text { Weighted } \\
\text { Coefficients }\end{array}$ & $4,106,499.58$ & $4,106,499.58$ & $3,612,783.78$ & $3,465,981.07$ & $4,433,157.03$ & $4,251,538.84$ & $2,890,561.50$ \\
\hline 7 days $12 \mathrm{~h}$ & $\begin{array}{l}\text { Dominant } \\
\text { Order Main } \\
\text { Criteria }\end{array}$ & $4,636,346.81$ & $4,636,346.81$ & $3,612,783.78$ & $3,465,981.07$ & $4,433,157.03$ & $4,517,685.95$ & $2,890,561.50$ \\
\hline $\begin{array}{l}7 \text { days } 12 \mathrm{~h} \text {, } \\
\text { with } \\
\text { maintenance }\end{array}$ & $\begin{array}{l}\text { Research } \\
\text { Coefficients }\end{array}$ & $2,881,509.16$ & $3,046,471.71$ & $3,032,738.00$ & $3,021,756.63$ & $3,627,350.21$ & $3,162,347.39$ & $2,074,101.03$ \\
\hline $\begin{array}{l}7 \text { days } 12 \mathrm{~h} \text {, } \\
\text { with } \\
\text { maintenance }\end{array}$ & $\begin{array}{l}\text { Equal } \\
\text { Weighted } \\
\text { Coefficients }\end{array}$ & $3,360,016.23$ & $3,512,442.62$ & $3,032,738.00$ & $3,021,756.63$ & $3,627,350.21$ & $3,590,159.63$ & $2,170,017.06$ \\
\hline $\begin{array}{l}7 \text { days } 12 \mathrm{~h} \text {, } \\
\text { with } \\
\text { maintenance }\end{array}$ & $\begin{array}{l}\text { Dominant } \\
\text { Order Main } \\
\text { Criteria }\end{array}$ & $3,971,328.75$ & $4,091,049.29$ & $3,032,738.00$ & $3,021,756.63$ & $3,627,350.21$ & $3,705,348.43$ & $2,170,017.06$ \\
\hline 7 days $24 \mathrm{hr}$ & $\begin{array}{l}\text { Research } \\
\text { Coefficients }\end{array}$ & $3,798,518.56$ & $3,798,518.56$ & $3,612,783.78$ & $3,465,981.07$ & $4,433,157.03$ & $4,048,355.79$ & $5,175,435.51$ \\
\hline 7 days 24 hr & $\begin{array}{l}\text { Equal } \\
\text { Weighted } \\
\text { Coefficients } \\
\text { Dominant }\end{array}$ & $4,106,499.58$ & $4,106,499.58$ & $3,612,783.78$ & $3,465,981.07$ & $4,433,157.03$ & $4,251,538.84$ & $5,158,554.11$ \\
\hline 7 days $24 \mathrm{hr}$ & $\begin{array}{l}\text { Order Main } \\
\text { Criteria }\end{array}$ & $4,636,346.81$ & $4,636,346.81$ & $3,612,783.78$ & $3,465,981.07$ & $4,433,157.03$ & $4,517,685.95$ & $5,111,979.01$ \\
\hline $\begin{array}{l}7 \text { days } 24 \mathrm{~h} \text {, } \\
\text { with } \\
\text { maintenance }\end{array}$ & $\begin{array}{l}\text { Research } \\
\text { Coefficients }\end{array}$ & $2,881,509.16$ & $3,046,471.71$ & $3,032,738.00$ & $3,021,756.63$ & $3,627,350.21$ & $3,162,347.39$ & $4,353,515.80$ \\
\hline $\begin{array}{l}7 \text { days } 24 \mathrm{~h} \text {, } \\
\text { with } \\
\text { maintenance }\end{array}$ & $\begin{array}{l}\text { Equal } \\
\text { Weighted } \\
\text { Coefficients }\end{array}$ & $3,360,016.23$ & $3,512,442.62$ & $3,032,738.00$ & $3,021,756.63$ & $3,627,350.21$ & $3,590,159.63$ & $4,353,515.80$ \\
\hline $\begin{array}{l}7 \text { days } 24 \mathrm{~h} \text {, } \\
\text { with } \\
\text { maintenance }\end{array}$ & $\begin{array}{l}\text { Dominant } \\
\text { Order Main } \\
\text { Criteria }\end{array}$ & $3,971,328.75$ & $4,091,049.29$ & $3,032,738.00$ & $3,021,756.63$ & $3,627,350.21$ & $3,705,348.43$ & $4,675,502.41$ \\
\hline
\end{tabular}




\section{CONCLUSIONS}

The Moora reference point model produced maximum total order revenue 12 times in a total of 27 planning scenarios, run by three different weighting factors of three different data sets. The linear function 2 method produced maximum total order revenue in 10 scenarios and linear function 1 in five scenarios. On the other hand, Moora method produced five times, while the weighted Moora presented the best total order revenue as decision support. Since the data sets are entirely independent of each other, each data set is considered in its own rather than in terms of system performance. Because the processing of orders with different criteria is different, the ranking and the proposed results link only the corresponding order pool (data set).

The proposed methods in delivery date and order ranking studies compare the performance of FCFS and EDD methods to the performance of new methods. In this study, FCFS and EDD methods have been found to be the most unsuccessful methods in promising maximum order revenue. This is consistent with the literature [1, 24-29]. The relevant literature generally consists of theoretical studies on processing time and cost calculations. However, in this study, new methods have been proposed, and by going beyond the theory, an application has been developed to contribute to the real business process. In the same planning group, the method of providing the best return within the varying weight coefficients was the linear function 2 method with 6 top scores. However, the Moora reference point method has produced the best revenue for three times. The decision support system has also shown that producing orders according to FCFS or EDD does not contribute positively to a firm's revenue. Participants of the study do not use any process to sort orders. They accept orders based on FCFS or EDD. For this reason, a new and easy work process for order sorting is also proposed. All methods used in this study, except FCFS and EDD, were used for the first time for order sorting problems. In addition, a study has been conducted for the first time with seven methods at the same time and a single screen order sorting and delivery date. This system, which will be operated according to the criterion weights determined by the marketing managers, is presented as a practical way to increase firms' revenues.

Non-woven manufacturers take orders immediately to the production plan. Instead, they can generate more revenue using the methods proposed in the study. For this, it is sufficient to use the results of the method which proposes the best revenue by collecting the orders in a pool and then evaluating them. In this way, non-woven manufacturers will increase their revenues and profitability by using their capacities more efficiently. Besides, the literature on delivery date and order sorting has been provided with a new perspective about an order-sorting decision support system, a product that can be used by end users and administrative staff. In subsequent studies, production scenarios can be developed for different sectors. Weight coefficients were obtained by the AHP method in the study. In subsequent studies, weight coefficients that yield better results can be investigated using a variety of techniques such as artificial intelligence anddata mining.

\section{ACKNOWLEDGEMENT}

This article has been produced from the doctoral thesis titled "Order Delivery Date Determination with Multicriteria Decision Support Model and Revenue Approach" which was published on 23.02.2018 under the consultancy of the 2nd author by the 1st author in the field of Informatics Department of İstanbul University Institute of Science and Technology.

\section{REFERENCES}

1. Guhlich, H., Fleischmann, M., \& Stolletz, R., (2015), Revenue management approach to due date quoting and scheduling in an assemble-to-order production system. OR Spectrum, 37(4), 951-982.

2. Ilić, A., (2015), On the variable common due date, minimal tardy jobs bicriteria two-machine flow shop problem with ordered machines. Theoretical Computer Science, 582, 70-73.

3. Jagan, D., Senthilvel, A. N., Prabhakar, R., \& Maheswari, S. U., (2015) Analysis for Maximal Optimized Penalty for the Scheduling of Jobs with Specific Due Date on a Single Machine with Idle Time. Procedia Computer Science, 47, 247-254.

4. Demir, H. I., Uygun, O., Cil, I., Ipek, M., \& Sari, M., (2015), Process Planning and Scheduling with SLK Due-Date Assignment where Earliness, Tardiness and Due-Dates are Punished. Journal of Industrial and Intelligent Information, 3(3), 173-180.

5. Çakar, T., Köker, R., \& Canay, O., (2015), A New Neuro-Dominance Rule For Single-Machine Tardiness Problem With Double Due Date. Neural Computing And Applications, 26(6), 1439-1450.

6. Baker, K. R., \& Trietsch, D., (2015), Trading off due-date tightness and job tardiness in a basic scheduling model. Journal of Scheduling, 18(3), 305-309.

7. Assarzadegan, P., \& Rasti-Barzoki, M., (2016), Minimizing sum of the due date assignment costs, maximum tardiness and distribution costs in a supply chain scheduling problem. Applied Soft Computing, 47, 343356.
8. Low, C., Li, R. K., \& Wu, G. H., (2016), Minimizing Total Earliness and Tardiness for Common Due Date Single-Machine Scheduling with an Unavailability Interval. Mathematical Problems in Engineering, Article ID 6124734, 12 pages, doi:10.1155/2016/6124734

9. Li, S. S., \& Chen, R. X., (2017), Common due date assignment and cumulative deterioration scheduling on a single machine. Engineering Optimization, 49(6), 976-989.

10. Zhao, C., (2016), Common due date assignment and single-machine scheduling with release times to minimize the weighted number of tardy jobs. Japan Journal of Industrial and Applied Mathematics, 33(1), 239249.

11. Drwal, M., (2018), Robust Scheduling To Minimize The Weighted Number Of Late Jobs With Interval Due-Date Uncertainty. Computers \& Operations Research, 91, 13-21.

12. Schäfer, R., Chankov, S., \& Bendul, J., (2016), What is Really "OnTime"? A Comparison of Due Date Performance Indicators in Production. Procedia CIRP, 52, 124-129.

13. Low, C., Li, R. K., Wu, G. H., \& Huang, C. L., (2015), Minimizing The Sum Of Absolute Deviations Under A Common Due Date For A SingleMachine Scheduling Problem With Availability Constraints. Journal Of Industrial And Production Engineering, 32(3), 204-217.

14. Canıyılmaz, E., Benli, B., \& Ilkay, M. S., (2015), An Artificial Bee Colony Algorithm Approach For Unrelated Parallel Machine Scheduling With Processing Set Restrictions, Job Sequence-Dependent Setup Times, And Due Date. The International Journal Of Advanced Manufacturing Technology, 77(9-12), 2105-2115. 
15. Zahedi, Z., Samadhi, T., Suprayogi, S., \& Halim, A., (2016), Integrated batch production and maintenance scheduling for multiple items processed on a deteriorating machine to minimize total production and maintenance costs with due date constraint. International Journal of Industrial Engineering Computations, 7(2), 229-244.

16. Lin, Y. K., \& Huang, D. H., (2017), Reliability analysis for a hybrid flow shop with due date consideration. Reliability Engineering \& System Safety.

17. Shabtay, D., Steiner, G., \& Zhang, R., (2016), Optimal Coordination O Resource Allocation, Due Date Assignment And Scheduling Decisions. Omega, 65, 41-54.

18. Demir, H. I., Cil, I., Uygun, O., Simsir, F., \& Kokcam, A. H., (2016) Process Planning And Weighted Scheduling With Wnoppt Weighted Due-Date Assignment Using Hybrid Search For Weighted Customers. International Journal Of Science And Technology, 2(1), 1-19.

19. Demir, H. İ., \& Erden, C., (2017), Solving process planning and weighted scheduling with WNOPPT weighted due-date assignment problem using some pure and hybrid meta-heuristics. Sakarya Üniversitesi Fen Bilimleri Enstitüsü Dergisi, 21(2), 210-222.

20. Samarghandi, H., \& Behroozi, M., (2016), An Enumeration Algorithm for the No-Wait Flow Shop Problem with Due Date Constraints. IFACPapersOnLine, 49(12), 1803-1808.

21. Kuroda, M., (2016), Integration of product design and manufacturing through real-time due-date estimation and scheduling systems. Journal of Advanced Mechanical Design, Systems, and Manufacturing, 10(3)

22. Nurainun, T., Fudholi, A., Hartati, M., Yendra, R., \& Kusumanto, I., (2016), A Multi Due Date Batch Scheduling Model on Dynamic Flow Shop to Minimize Total Production Cost. Contemporary Engineering Sciences, 9(7), $315-324$.
23. Lödding, H., \& Piontek, A., (2017), The surprising effectiveness of earliest operation due-date sequencing. Production Planning \& Control, 28(5), 459-471.

24. Carr, S., \& Duenyas, I., (2000), Optimal admission control and sequencing in a make-to-stock/make-to-order production system. Operations research, 48(5), 709-720.

25. Lewis, H. F., \& Slotnick, S. A., (2002), Multi-period job selection: planning work loads to maximize profit. Computers \& Operations Research, 29(8), 1081-1098.

26. Keskinocak, P., Ravi, R., \& Tayur, S., (2001), Scheduling and reliable lead-time quotation for orders with availability intervals and lead-time sensitive revenues. Management Science, 47(2), 264-279.

27. Slotnick, S. A., \& Morton, T. E., (2007), Order acceptance with weighted tardiness. Computers \& Operations Research, 34(10), 3029-3042.

28. Deng, H., Wang, Q., Leong, G. K., \& Sun, S. X., (2008), The usage of opportunity cost to maximize performance in revenue management. Decision Sciences, 39(4), 737-758.

29. Oğuz C., Salman, F. S., \& Yalçın, Z. B., (2010), Order acceptance and scheduling decisions in make-to-order systems. International Journal of Production Economics, 125(1), 200-211.

30. Aktürk, C., \& Gülseçen, S. (2018). A Multi-Criteria, Multi-Method Decision Support System for the Order Delivery Date Problem. Institute of Business Administration-Management Journal, 29(84). 